\title{
THE NATIONAL INSTITUTE OF AGRICULTURAL BOTANY
}

\begin{abstract}
$\mathrm{O}^{\mathrm{N} s}$ $\mathrm{NE}$ of the objects of the National Institute of Agricultural Botany is promoting the improvement of existing varieties of seeds, plants and crops in the United Kingdom and aiding the introduction or distribution of new varieties, and the annual report recently published indicates the wide range of work being undertaken to further this object*.

The work of the Trials Branch resulted in the addition of six varieties of cereals to the recommended list, while fifty-eight varieties were not approved. Short notes are given on the performance of many of these. Similar reports are given on preliminary results for other crops, and in the vegetable trials special attention has been paid to varieties suitable for quick freezing. Yield trials on recently introduced and foreign varieties of potato were continued at various centres. Progress is reported in attempts to explain stem-end blackening in the cooked potato. These chemical investigations, being conducted in collaboration with the Low Temperature Station, Cambridge, have shown that differences in $p H$ have much less effect on the amount of discoloration than differences in the concentration of citric acid. It has also been demonstrated that the inerease in

* National Institute of Agricultural Botany. Thirty-ninth Report and Accounts, 1958. Pp. 56. (Cambridge : National Institute of Agricultural Botany, 1959.$)$
\end{abstract}

discoloration in stored potato is associated with a sudden decrease in citric acid when sprouting begins.

The Seed Production Branch records considerable progress in the development of the arrangements for seed approval and certification. Almost 130,000 acres were inspected under the Cereal Field Approval Scheme. The report of the Official Seed Testing Station directs attention to some interesting differences in the proportions of varieties of cereals which failed to reach the minimum authorized percentage germination for declaration as laid down by the Seed Act. The varieties Cappelle Desprez and Koga II both represented about 25 per cent of the wheat samples reaching the Seed Testing Station, while Proctor represented nearly 50 per cent of the barley samples. One of the investigations in progress in the Seed Testing Station is concerned with the persistence of weed seeds in the soil and factors concerned in their germination and establishment. Detailed reports have been prepared of the investigations into the role of oxygen in the dormancy of wheat varieties and of the effects of maturation on the embryo, the endosperm and the covering layers. A comparative study is in progress of the maturation in two barley varieties, Domen and Herta, which differ markedly in their germination behaviour at harvest.

\section{AUTOMATIC CONTROL IN SOVIET INDUSTRY}

$\mathrm{T}$ HE Department of Scientific and Industrial Research has issued a report giving the observations of a team of six British engineers who visited the Soviet Union in May 1959 to study progress in automatic control of industrial production (Automatic Control in Soviet Industry. Pp. 64. London : Depart. ment of Scientific and Industrial Research, 1959).

Besides industrial establishments, the team visited research institutes under the Academy of Sciences, U.S.S.R., the Central Laboratory for Automation, Moscow, various educational establishments, the Computing Centre of the Mechanized Faculty, University of Moscow, and the Computer Centre of the Academy of Sciences, Moscow. The team considered its chief function to be the opening of channels of communication and the establishment of personal relations, and in this the visit appeared to be most successful. A fow firm conclusions were drawn from what was seen. Work is in progress in most sections of the field of industrial control systems and most distinctive classes of device are in process of development. Analogue computers are freely used and digital machines are rapidly becoming easily available, though generally this work appears to be less advanced than in Britain. Considerable activity was noted on control in the steel industry, particularly in developing integrated process-control simulators, and work is also well advanced in telemetering and on the control of electric power systems with long transmission lines. Less attention appears to be paid to project evaluation than is usual in industrial research in Britain.

Great potential is being built up for further developments in automatic control and automation in industry in the form of large well-equipped laboratories and trained engineers. Of five research institutes visited, two had been established for only two years and one for three, and the Central Institute for Automation of the Ukraine at Kiev plans to increase its existing staff of 700 to 4,000 in three to four years. Some 83,000 students were said to have graduated in 1958, and the connexion between teaching, research and industry is good, with much interflow of staff. The team gained the impression that in a few years the application of automatic control in Soviet industry will have overtaken that in Britain, but there is at present little evidence to judge how good Soviet engineers will prove in the further stage when leadership depends upon breaking new ground, though their present level of achievement in basic theoretical work is high.

The report stresses the desirability of extending communications with the U.S.S.R. in this field, the importance of more British engineers acquiring sufficient knowledge of Russian to use Soviet technical literature, and the friendliness with which the team was received. Some suggestions are made regarding the arrangement of future visits. 